\title{
Carbon C 13 Acetate
}

National Cancer Institute

\section{Source}

National Cancer Institute. Carbon C 13 Acetate. NCI Thesaurus. Code C116714.

The non-radioactive naturally occurring isotope of acetate, carbon C 13 acetate, with potential use for metabolic tumor imaging upon nuclear magnetic resonance (NMR) spectroscopy. Upon infusion, carbon C 13 acetate is taken up by cancer cells and is utilized by metabolic pathways in the tumor cell. Specifically, the tumor cells oxidize acetate, in the form of acetyl coenzyme A (acetyl-CoA), in the citric acid cycle. Upon 13CNMR, the metabolic phenotype of a tumor can be assessed. Certain alternative metabolic pathways are activated in tumor cells and use substrates other than glucose, such as acetate, for acetyl-CoA production. 